\title{
Methods for the measurement of ferrite content in multipass duplex stainless steel welds
}

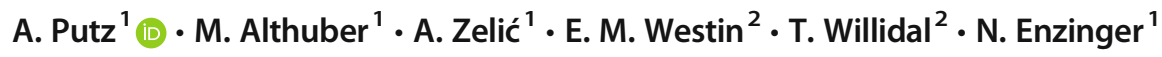

Received: 26 September 2018 / Accepted: 27 February 2019 / Published online: 10 April 2019

(C) The Author(s) 2019

\begin{abstract}
The phase balance is commonly determined as a part of the duplex stainless steel (DSS) welding procedure qualification. In this work, the aim was to find a reliable, but still fast method to measure the ferrite content of DSS welds. Four methods were compared: image analysis with light optical metallography, magnetic measurements with Feritscope and Magne-Gage, and X-ray diffractometry (XRD). Image analysis with a magnification of $\times 500$ was concluded to be most accurate on condition that the image quality was sufficiently high. The best contrast for image analysis was achieved by covering all surfaces apart from the part of interest with adhesive tape and etching the sample in a modified Beraha II solution. The Feritscope systematically underestimated the average ferrite volume fraction compared with image analysis, and a correction factor of 1.1 is suggested. Magne-Gage in turn resulted in considerably higher ferrite numbers as compared with the Feritscope and would require a correction factor of 1.18. Besides the long duration of XRD measurements, the method proved unsuitable for ferrite measurement due to the coarse texture of the microstructure.
\end{abstract}

Keywords Duplex stainless steel $\cdot$ Ferrite measurement $\cdot$ Ferrite content $\cdot$ Image analysis $\cdot$ Feritscope

\section{Introduction}

Duplex stainless steels (DSSs) combine the advantages of ferritic and austenitic stainless steels. The properties are being determined by the chemical composition and the phase balance. The high chromium content and alloying with nitrogen contribute to high strength and the resistance to intergranular corrosion, and stress-corrosion cracking is better than for most austenitic grades. As compared with ferritic alloys, DSSs are more ductile, less sensitive to hydrogen embrittlement and more resistant to localized and general corrosion. The corrosion resistance increases with the chromium, molybdenum, and nitrogen content, but high levels of chromium and

Recommended for publication by Commission IX - Behaviour of Metals Subjected to Welding

A. Putz

andrea.putz@tugraz.at

1 Institute of Materials Science Joining and Forming, Graz University of Technology, Kopernikusgasse, 24, 8010 Graz, Austria

2 voestalpine Böhler Welding Austria GmbH, Böhler-Welding-St. 1, 8605 Kapfenberg, Austria molybdenum also increase the risk of formation of intermetallic phases at an elevated temperature [1]. While the base metal consists of approximately equal proportions of ferrite and austenite, the weld metal can show a significantly wider range. When welding, the solidification is normally fully ferritic and austenite forms upon cooling [2]. The microstructure of welds can be influenced by the heat input and cooling rate, mainly by adjusting the arc energy and limit the inter-pass temperature to $100-150{ }^{\circ} \mathrm{C}$. Although preheating is rarely applied for welding DSS, it might be necessary if the plates are very thick and/or heavily restrained to reduce cooling rates and stress levels. If the temperature is lower than room temperature, preheating up to $50-80{ }^{\circ} \mathrm{C}$ can be performed to guarantee dry joint surfaces. The weld metal chemical composition, however, has the largest influence on the final microstructure. This is in turn a function of the composition of the steel grade, filler metal, and shielding gas. The joint preparation affects the dilution from the base material. A final post-weld heat treatment dissolves intermetallic phases, and the austenite content increases, but is for practical reasons rarely used in practice [3].

Filler metals for DSS are mainly of matching composition or slightly over-alloyed compared with the base material to compensate element loss and segregation in the weld metal. 
To ensure sufficient austenite formation, however, the specially developed fillers are over-alloyed by $2-4 \%$ with nickel [4]. In the case of multilayer welding, this means that the nickel content in the subsequent weld beads increases and more austenite can be formed. Another effect of multilayer welding is the formation of secondary austenite due to reheating by deposition of subsequent beads [5]. Welding without filler material is not recommended as this can lead to a primarily ferritic weld metal with lower pitting resistance and impact toughness [6]. The use of austenitic fillers, on the other hand, can change the solidification mode to ferritic-austenitic, which can lead to lower strength and resistance to stress-corrosion cracking [7]. Duplex alloys are not often subject to any form of cracking, but with partly austenitic solidification or very high austenite levels, there is an increased risk of solidification cracking [8].

The mechanical properties and corrosion resistance are related to the duplex microstructure, and therefore, the ferrite content is important and sometimes specified. Some industry specifications, such as NORSOK M-601 [9], set the limit for the base material at 40-60\% ferrite and 35-65\% for welds, while others state $30-70 \%$. The microstructure is not a property itself, but an unbalanced ferrite/austenite ratio may cause inadequate mechanical and corrosion properties, and therefore, requires further investigations.

Based on the base material and filler metal composition, it is possible to make a rough estimation of the ferrite content in the weld metal. Alongside with the somewhat outdated Schaeffler diagram [10] and DeLong diagram [11], the WRC1992 diagram [12] is considered to be most appropriate to predict the amount of ferrite in DSSs [13]. The calculated chemical composition of the weld deposit is divided into the $\mathrm{Cr}$ and $\mathrm{Ni}$ equivalents, and the ferrite number $\mathrm{FN}$ can be found in the diagram. Since the nickel contents in the base material and filler metal differ, the amount of diluted base material is crucial for the final weld metal composition. Another weakness is that element loss due to evaporation from the filler and weld metal, depending on the arc energy and shielding gas composition, is not taken into account. Both cases would require an analysis of the actual weld metal deposit to get the exact composition. In addition, important factors such as cooling rate and reheating of passes are not taken into account and the prediction may not be accurate.

The ferrite content can be measured by magnetic methods, quantitative metallography like for example planimetry, lineal analysis, or differential point counting [14] or by different methods using electron diffraction such as X-ray diffractometry (XRD) or electron backscatter diffraction (EBSD). As XRD, EBSD and manual counting in accordance with ASTM E 562 [6] are rather time-consuming and thus fairly expensive; image analysis and magnetic measurements with Feritscope are more frequently used.

In image analysis, the fraction of each phase is measured on etched samples in high magnification using a light optical microscope with special software. This is considered to be one of the most accurate techniques $[15,16]$ and together with point counting, usually the only method accepted when developing welding procedure specifications. The precision, however, is dependent on the surface quality of the sample; scratches and limited etch quality are influencing the final result. As mentioned in ASTM E 562, the magnification should be sufficiently high to clearly resolve the microstructure. As the magnification is increased, the field area decreases, and the field-to-field variability increases. This requires a greater number of fields, but at the same time, higher resolution means that small fractions of, for instance, secondary austenite is included in the measurement for better accuracy. For duplex welds, the magnification is often set to $\times 500$ and small welds may even require $\times 1000$. When examining large amounts of specimens, this is a rather a time-consuming operation.

Image analysis requires skilled operators and highly developed microscopes and software, and the special polishing and etching procedure make the method quite ineffective. Magnetic measurements are thus often an attractive alternative. A Feritscope uses the principle of magnetic induction for ferrite measurement and measures all magnetic components in the otherwise non-magnetic structure. On the field, Feritscope may be the only practical possibility of being a nondestructive method. Magne-Gage measures, by use of a spiral spring, the force which is necessary to remove a permanent magnet from the surface of a specimen. The ferrite number can be calculated according to the previous calibration using a primary set of standards [17]. The Magne-Gage instrument has in many laboratories been replaced by the Feritscope but has historically played an important role for ferrite measurements. Many of the weld metal standards used today to calibrate instruments such as the Feritscope have been produced and assigned an FN using a Magne-Gage. Another quantitative method to determine the relative amounts of ferrite in DSS is X-ray diffractometry (XRD) by measuring the peak positions and intensity of deflected X-rays which are particular for a specific crystalline phase and its weight fraction [18].

The aim of this work was to find a reliable method to measure the ferrite content of multipass $22 \mathrm{Cr}$ duplex welds, which is fast but still as accurate as possible. Different ways to determine the ferrite fraction are evaluated.

\section{Experimental}

The base material was 30 -mm-thick $22 \mathrm{Cr}$ duplex stainless $1.4462 /$ UNS S32205 with the composition given in Table 1. Double fillet welds were welded with the flux-cored arc welding (FCAW) process in $\mathrm{PB} / 2 \mathrm{~F}$ position. The vertical plate had a bevel angle of $55^{\circ}$ and $50^{\circ}$ and both plates got clamped firmly. The T-joint preparation is shown in Fig. 1. 
Table 1 Chemical composition of DSS base material 1.4462/UNS S32205, wt $\%$

\begin{tabular}{lllllll}
\hline $\mathrm{C}$ & $\mathrm{Si}$ & $\mathrm{Mn}$ & $\mathrm{Cr}$ & $\mathrm{Ni}$ & $\mathrm{Mo}$ & $\mathrm{N}$ \\
\hline 0.022 & 0.3 & 1.8 & 22.8 & 4.6 & 2.5 & 0.20 \\
\hline
\end{tabular}

The filler metal was a flux-cored wire of T $2293 \mathrm{~N} \mathrm{~L} \mathrm{R/}$ E2209T0 type (Table 2). The welding parameters were set to achieve spray arc transfer and to keep the arc energy at $15 \mathrm{~kJ} /$ $\mathrm{mm}$ (Table 3). One hundred percent $\mathrm{CO}_{2}$ was used as shielding gas and the inter-pass temperature was kept below $150{ }^{\circ} \mathrm{C}$.

For this work, three specimens with one, two, and three layers were investigated. To be able to study these separately, the experimental setup was selected to vary the weld length. The first pass, the root, was as long as the base plate $(320 \mathrm{~mm})$. Every following layer was shortened by a quarter of the previous layer.

Cross-sections were cut and embedded with epoxy hot mounting resin. The detailed procedure for grinding and polishing is summarized in Table 4.

As the most important factor for image analysis is high contrast, different etchants such as Beraha II, Murakami, V2A, Lichtenegger+Bloech, oxalic acid, sodium hydroxide solution, and $\mathrm{KOH}$ were applied on polished base metal cross-sections. The selection of these etchants was based on the work by Petzow [19].

Ferrite measurement of welds was performed at a magnification of $\times 500$ as recommended for point counting method in

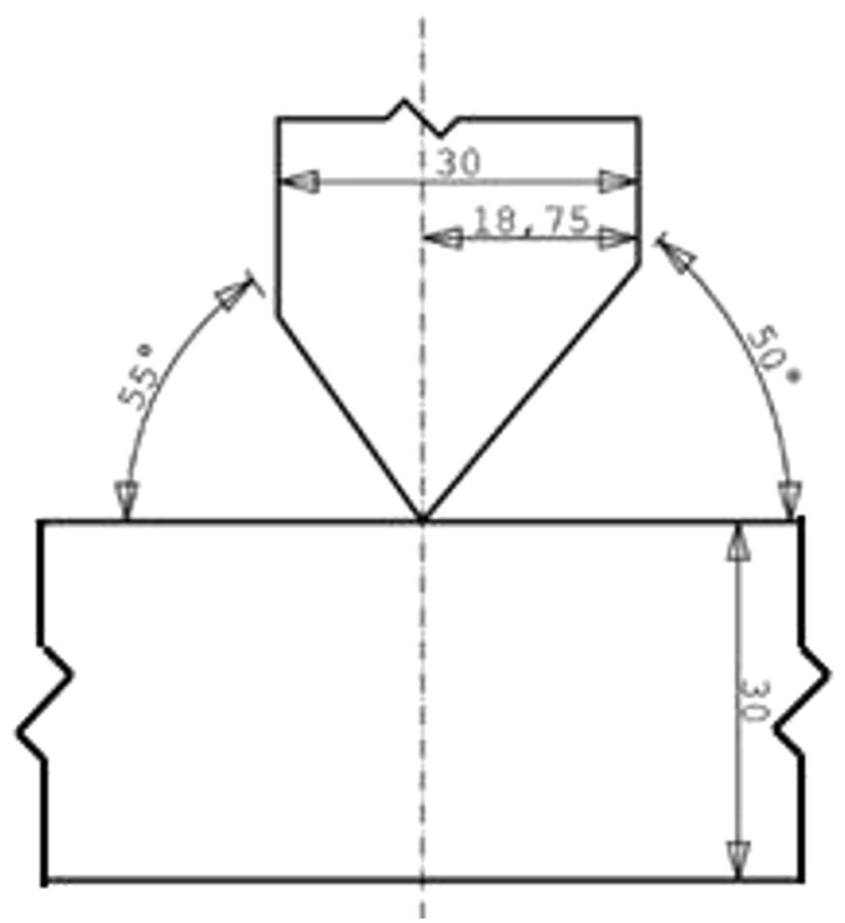

Fig. 1 Joint preparation
Table 2 Chemical composition of DSS flux-cored wire all-weld metal, $\mathrm{wt} \%$

\begin{tabular}{lllllll}
\hline $\mathrm{C}$ & $\mathrm{Si}$ & $\mathrm{Mn}$ & $\mathrm{Cr}$ & $\mathrm{Ni}$ & $\mathrm{Mo}$ & $\mathrm{N}$ \\
\hline 0.030 & 0.9 & 0.6 & 22.7 & 9.0 & 3.15 & 0.135 \\
\hline
\end{tabular}

ASTM E562 [20]. Each weld bead was divided into five areas, and for each area, five pictures were taken in a light optical microscope - a total of 25 images per weld bead. The ferrite content was measured based on the phase fractions using the software AxioVision from Zeiss. The software counts all "dark" pixels, which are ferrite when etched with Beraha II. If the polishing and etching are not perfect, the threshold can be adjusted manually or scratches can be painted over with the correct color. Hence, there might be an influence of the user's judgment. To investigate such possible influence of different users, two different operators were independently examining the same samples.

Measurements by Feritscope were performed on the crosssections prepared for image analysis using a Fischer Feritscope FMP30. For each bead, five different points were measured and reported as percent ferrite (\% ferrite) as well as ferrite number (FN).

Measurements by Magne-Gage were also made individually for each bead. These measurements were repeated five times at the same point. Since the size of the probe was about the size of the bead itself, the entire bead is measured at once and not a specific area within a bead. Measurements were performed for the sample with one layer/one bead and two layers/three beads. As the second layer of the sample with three layers/six beads was somehow too small for the relatively large size of the probe, it was not possible to investigate the single-weld beads for this sample separately.

$\mathrm{X}$-ray diffraction analysis was performed on five different measuring points only on the cross-section with one layer/one bead and made on XRD data from a Discover (Bruker), $\mathrm{Cu}$ $\mathrm{K} \alpha$ radiation (1.54 $\AA$ ) with a LynxEye position-sensitive detector. Data was analyzed with the Rietveld method using the program Topas version 4 (Bruker). The data was collected between 47.5-93 $2 \theta$. In this range, austenite Bragg peaks with hkl 200, 220, and 311 and Bragg peaks with 200 and 211 can be found if present.

Table 3 Welding parameters

\begin{tabular}{llllll}
$\begin{array}{l}\text { Voltage } \\
\text { V }\end{array}$ & $\begin{array}{l}\text { Current } \\
\text { A }\end{array}$ & $\begin{array}{l}\text { Welding speed } \\
\mathrm{m} / \mathrm{min}\end{array}$ & $\begin{array}{l}\text { Arc energy } \\
\mathrm{kJ} / \mathrm{mm}\end{array}$ & $\begin{array}{l}\text { Wire feeding } \\
\mathrm{m} / \mathrm{min}\end{array}$ & Polarity \\
\hline 29 & 230 & 0.27 & 1.48 & 14 & $\mathrm{DC}+$ \\
\hline
\end{tabular}


Table 4 Preparation of stainless steel for image analysis

\begin{tabular}{lllll}
\hline Step & Grinding 1 & Grinding 2 & Polishing 1 & Polishing 1 \\
\hline Surface & SiC paper 1200 & MD - Largo & MD - Dac & MD - Chem \\
Suspension & Water & Dia Pro Largo 9 & Dia Pro Dac 3 & OPS \\
Rotation speed, rpm & 300 & 150 & 150 & 150 \\
Force/specimen, $N$ & 25 & 40 & 20 & 15 \\
Time, min & As needed & 5 & 4 & 3 \\
\hline
\end{tabular}

\section{Results}

Although all applied etchants revealed the microstructure (Fig. 2), the best contrast was achieved using Beraha II, and therefore, this etchant was selected to be used for all welded specimens in this work.

Without elucidating the microstructure properly, it was not possible to make reliable measurements. Despite the high
Fig. 2 Base material DSS etched using. a Beraha II: Ferrite dark, austenite bright. b Murakami: Ferrite brown, austenite white. c V2A: Ferrite light gray, austenite dark gray. d Lichtenegger+ Bloech: Ferrite light blue, austenite white. e Oxalic acid: Ferrite dark gray, austenite light gray. f NaOH: Ferrite blue, austenite yellow. g KOH: Ferrite dark, austenite bright
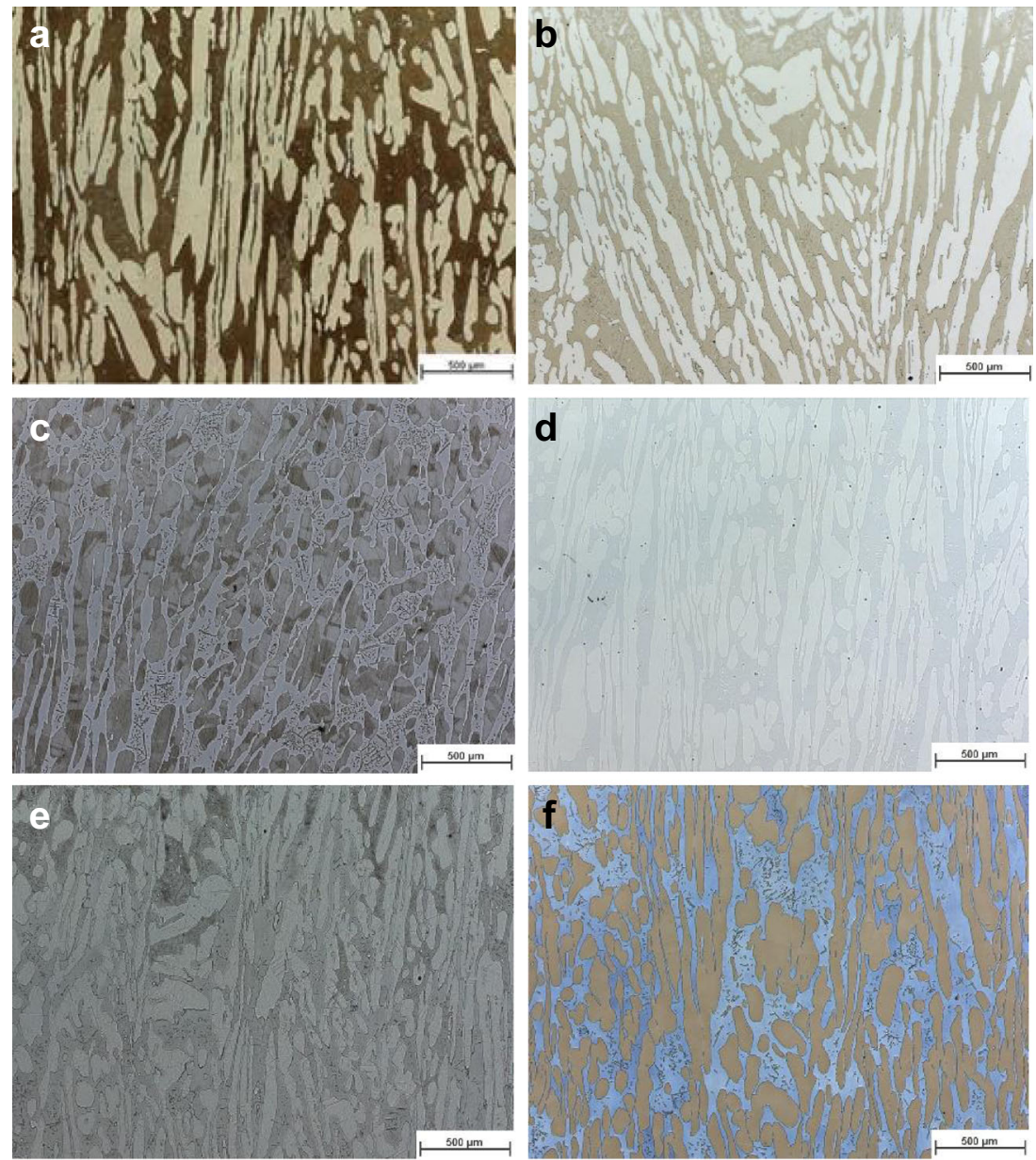




Fig. 3 a Inadequate and b adequate etching for image analysis after changing the etching procedure

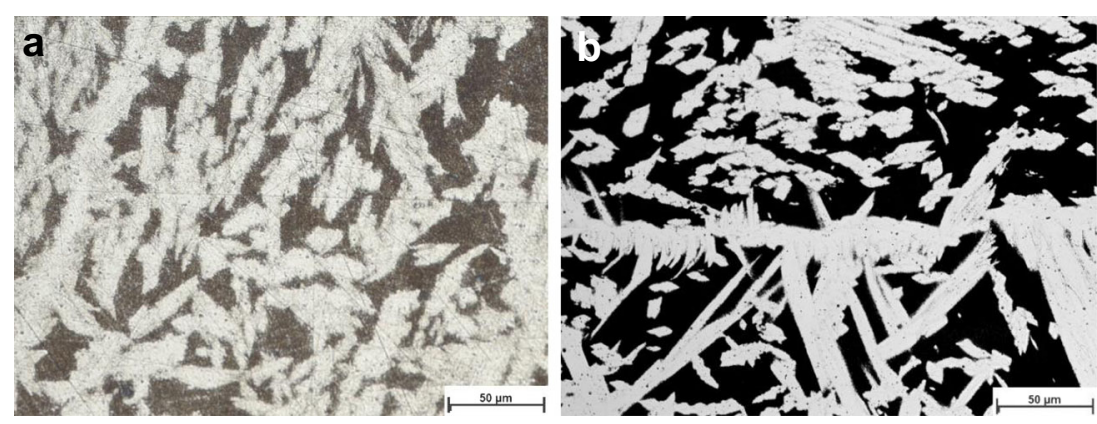

contrast on the base material, the surface quality of welds using Beraha II was not satisfactory (Fig. 3a). When two different operators measured the average ferrite content of samples with improper etching, unevenly etched parts were falsely counted as austenite and the scatter was fairly large. Comparing the results for Fig. 3a, user 1 measured a ferrite content of $42 \%$, while user 2 measured only $33 \%$. For this reason, the etching procedure needed to be improved. The first adjustment was to reduce the amount of potassium metabisulfite to max. $0.5 \mathrm{~g}$ per $100 \mathrm{ml}$ stock solution (Table 5). The second improvement was to etch the layers separately by covering all the unobserved areas with adhesive tape. This increased the image quality substantially (Fig. 3b). The difference in average value and standard deviation with improper and proper etching can be seen in Fig. 4.

With proper etching, the images could be evaluated by the software, the average ferrite content and the standard deviation for each area (Fig. 5), each weld bead, and the total weld can be calculated. Figure 6 shows the average ferrite content and standard deviation for the specimen with two layers/three beads for each local area (Fig. 6a), weld bead (Fig. 6b), and total weld (Fig. 6c).

As 25 images for every weld bead is fairly time-consuming for multipass welds, attempts were made to optimize the measurements. A first effort by reducing the magnification to $\times 50$ and taking fewer pictures was not effective as the resolution was insufficient to capture the small details. As shown in Fig. 6 , the values deviated and there was an inconsistency between the two operators. Using a magnification of $\times 50$ the first operator systematically underestimated the ferrite content, while the second consistently overestimated the ferrite content compared with the results using a magnification of $\times 500$ (Fig. 7).

Since the high magnification must be maintained, the second variable, the number of images, was reduced. One image

Table 5 Modified Beraha II

\begin{tabular}{lll}
\hline Stock solution & Distilled water & $800 \mathrm{ml}$ \\
& Hydrochloride acid & $400 \mathrm{ml}$ \\
& Ammonium bifluoride & $48 \mathrm{~g}$ \\
\multirow{2}{*}{ Add to $100 \mathrm{ml}$ of stock solution } & Potassium metabisulfite & $0.5 \mathrm{~g}$ \\
\hline
\end{tabular}

was randomly picked out of each area, and the average ferrite content was calculated again. This procedure was repeated five times to generate one image per area. Figure 8 shows the results from the optimized procedure as compared with the original method. The average ferrite content and standard deviation indicate that the results with the optimized method were within the standard deviation of the original method.

With the chosen procedure of image analysis, the evolution of ferrite content per weld bead can be viewed in detail in Fig. 9 .

The results of the measurements by Feritscope are shown as ferrite content in percentage (\% ferrite) in Fig. 10 and as ferrite number (FN) in Fig. 11. The standard deviation for the single beads was $1-4 \%$ ferrite when measurements were performed in percent ferrite and $2-5 \mathrm{FN}$ when ferrite number was measured.

Figure 12 shows the results from the Magne-Gage measurements in FN. The standard deviation of the repeated measurements for the single beads was about $1-8 \mathrm{FN}$.

Table 6 summarizes the measurements performed with XRD. The diffraction patterns showed heavy texturation, and this was accounted for using a spherical harmonics function when refining the data. Very little or no ferrite was measured for the first four samples $(0-7 \%)$, while the last sample showed $43 \%$.

\section{Discussion}

The difference in etching quality between the base material and the welded joints can possibly be explained by the difference in element distribution and variation in microstructure [8]. Most etching procedures have been developed for the base metal where the ferrite stabilizing elements are more concentrated in the ferrite and the austenite stabilizing elements in the austenite. In the weld metal, the nickel content is significantly higher due to the addition of filler metal, and the microstructure is primarily controlled by the distribution of nitrogen [21]. When etching the base material, there is only one type of microstructure present, while a welded sample contains base material, weld metal, and the heat-affected zone. In addition, there may be oxides and slag present in the weld cross-section. When etching a cross-section consisting of the base material, 
Fig. 4 Average ferrite content using image analysis on samples with inadequate and adequate etching
100

$$
90
$$




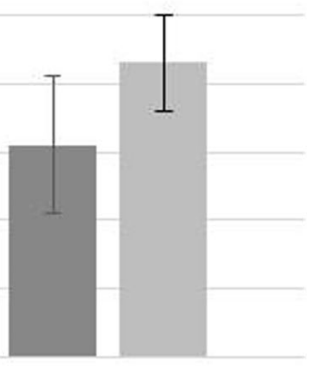

3 layers $=6$ beads

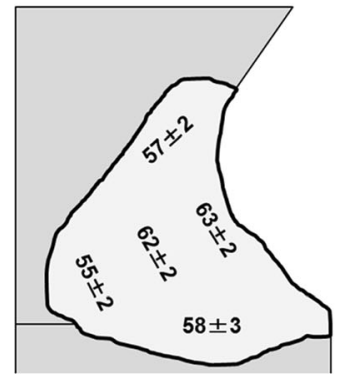

Fig. 5 Average ferrite content per local area with five images per area for all cross-sections

heat-affected zone, and weld metal, the result may thus be uneven as preferential etching may take place in the base material first and change the redox potential in the chemical solution. This problem can be solved by sealing off all other areas using adhesive tape. Then, only the area in focus will be etched and hence the quality increases.
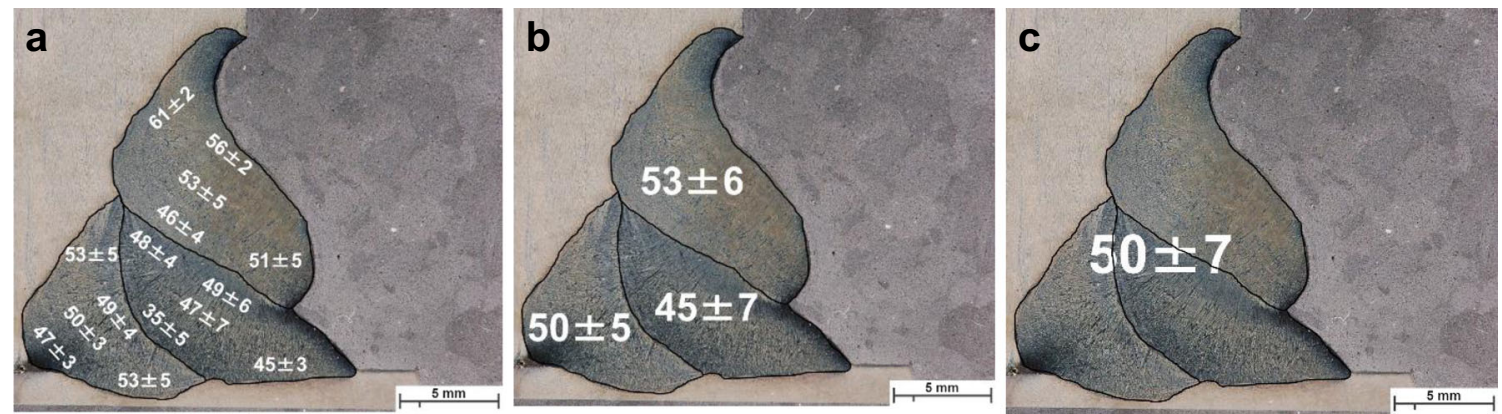

Fig. 6 Average ferrite content and standard deviation for each a local area, $\mathbf{b}$ weld bead, and $\mathbf{c}$ total weld 
Fig. 7 Comparison of ferrite content for a specimen with two layers $=$ three beads of magnification $\times 500$ vs. $\times 50$ for two different operators, user 1 vs. user 2

Fig. 8 Comparison of measured average ferrite content between 25 images vs. randomly distributed five images per bead

Fig. 9 Evolution of ferrite content measured using image analysis
100
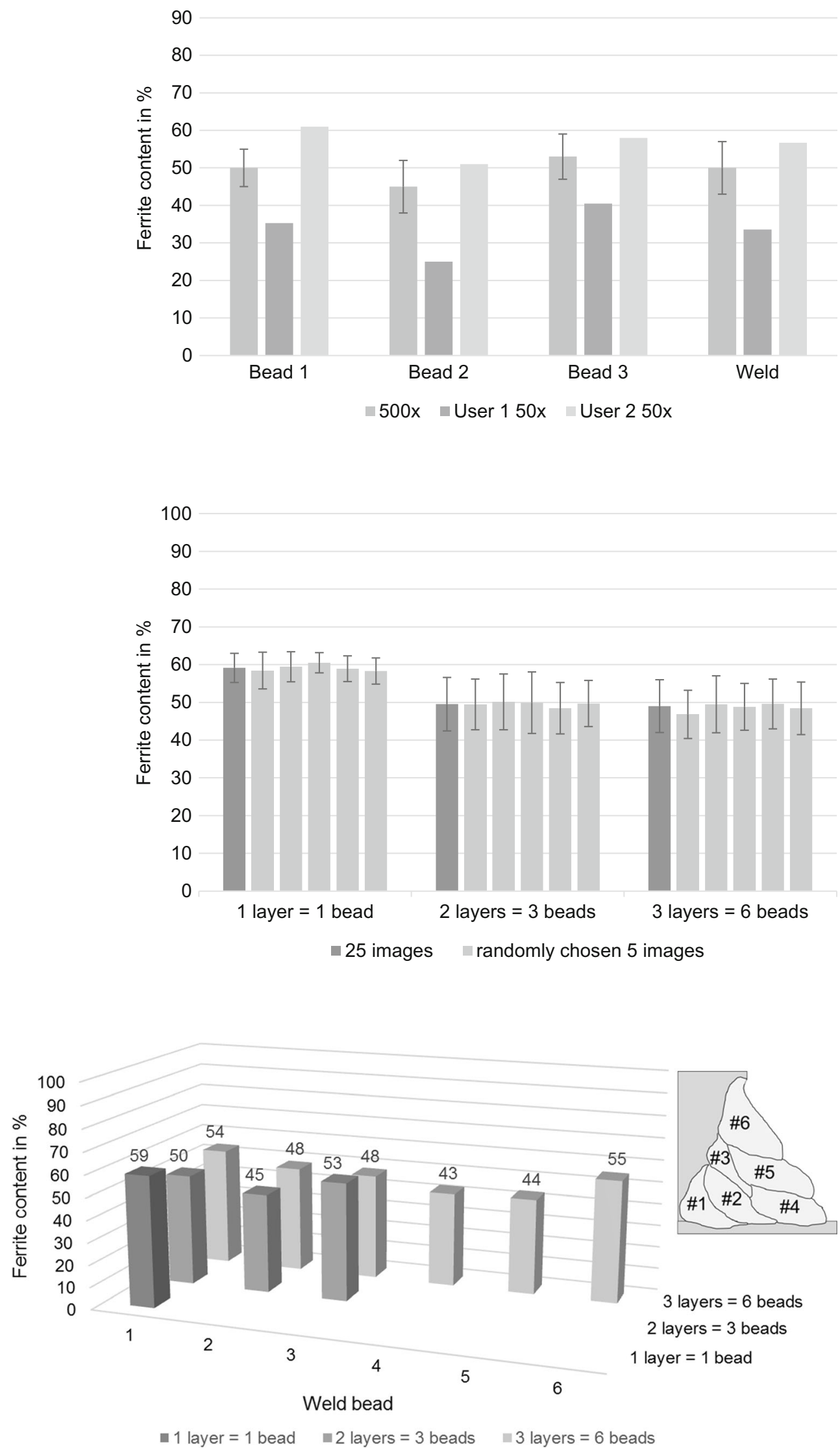
Fig. 10 Evolution of ferrite content in $\%$ ferrite measured using Feritscope

Fig. 11 Evolution of ferrite content in FN measured using Feritscope
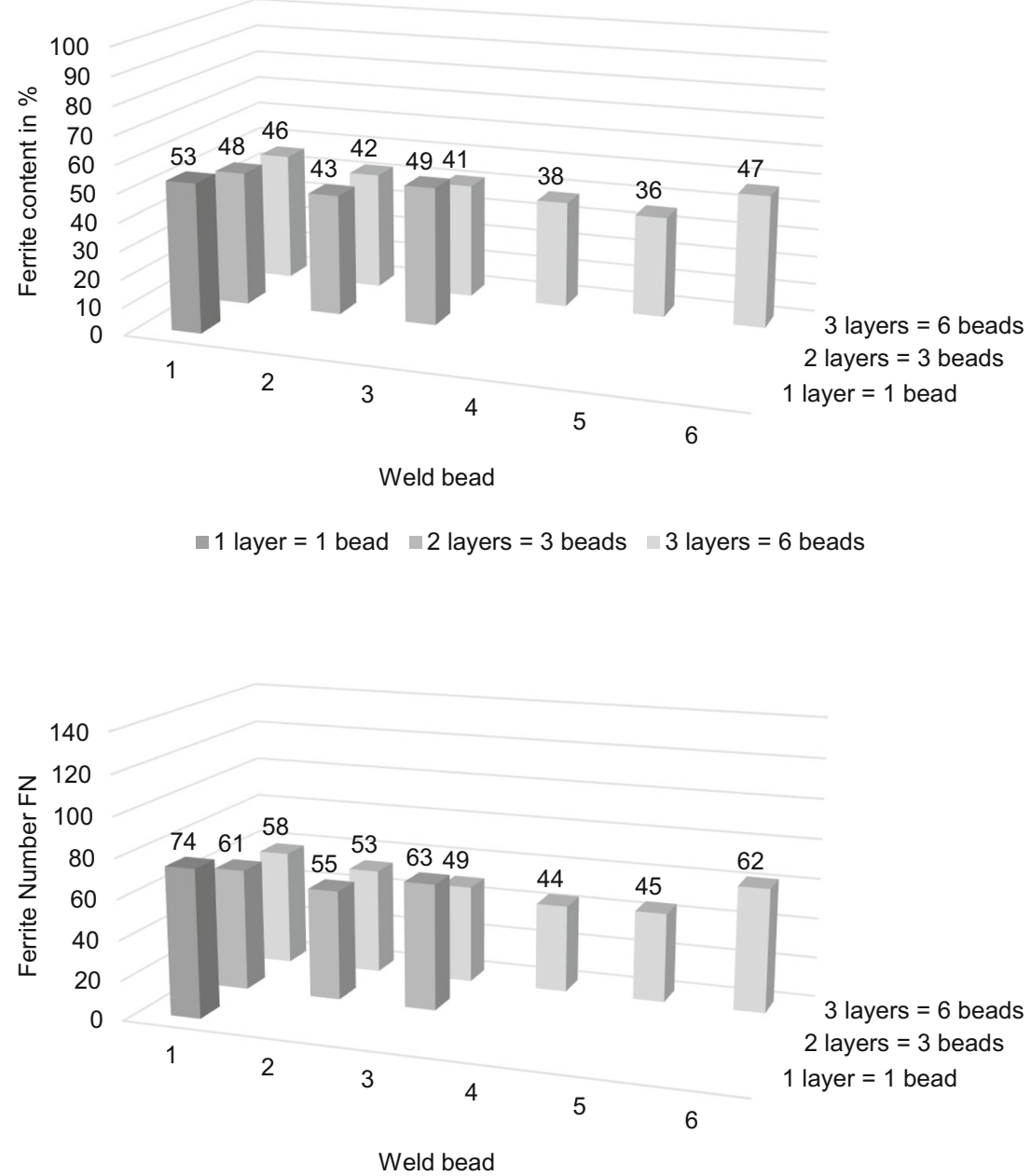

$\square$ layer $=1$ bead $\quad 2$ layers $=3$ beads $\quad 3$ layers $=6$ beads
The main advantage of image analysis is that there is additional photo evidence of the microstructure that can easily give a rough impression of the phase balance and be used in reports. On the other hand, the ferrite fraction might be overestimated since possible secondary austenite, which is finely distributed in the ferritic matrix of previous beads and forms during multipass welding, will not be etched properly and therefore not detected. This disadvantage could possibly be counteracted by using a higher magnification, but this would also mean a higher effort.
Fig. 12 Evolution of ferrite content in FN measured using Magne-Gage

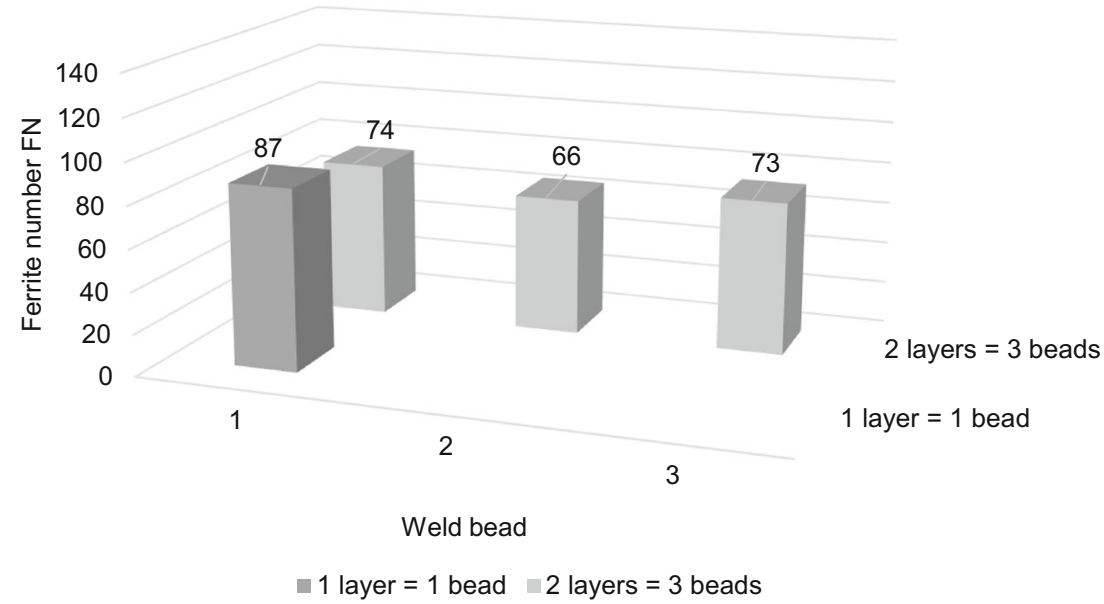


Table 6 Results of the XRD measurements for the sample with one layer/one bead

\begin{tabular}{ll}
\hline Measurement & $\%$ ferrite \\
\hline 01 & 0 \\
02 & 1 \\
03 & 0 \\
04 & 7 \\
05 & 43 \\
\hline
\end{tabular}

Figure 13 shows the ferrite content in \% ferrite of all three specimens measured by image analysis as compared with the Feritscope readings. The Feritscope values were systematically lower than that in image analysis. Multiplying the Feritscope results with a factor of 1.1, however, gives roughly the same result as with image analysis. This is in agreement with the work by Hosseini et al. [22] on superduplex stainless steel welds. The highest deviation can be observed for the sample with three layers/six beads which is up to $20 \%$. This is possibly related to the higher fraction of secondary austenite formed in multipass welds.

Another possible explanation for this deviation might be the internal calculation of the device from ferrite number to $\%$ ferrite (Fig. 14). The measurement is determined in ferrite number (FN), then computed according to Fischer's inhouse conversion relationship and displayed as percent ferrite. It is known that this converted ferrite measurement shows an uncertainty of $\pm 16 \%$ of the measurement, as indicated by the gray area above and below the conversion curve [23].

The ferrite number FN measured by Feritscope and MagneGage is shown in Fig. 15. In terms of ferrite number, the Magne-Gage instrument showed higher results compared with measurements with Feritscope for the samples with one layer/ one bead and two layers/three beads. Multiplying the ferrite number using the Feritscope by a factor of 1.18 gives roughly the same values as with Magne-Gage. The ferrite number measured by Magne-Gage of the sample with three layers/ six beads is not considered as the probe size was too large for the size of the single-weld beads.

The deviation may be explained by the calibration of the Magne-Gage. The calibration curve for $\mathrm{FN}>60$ showed some slight bend for higher dial readings. Hence, the assigned linear regression equation resulted in somewhat too high ferrite numbers and also a higher standard deviation. Apart from the difficulty to properly calibrate the particular instrument used in this investigation and finding an experienced operator, another problem is that the size, shape, and orientation of ferrite particles affect the readings of the Magne-Gage [24]. Although Magne-Gage is the only instrument which can be calibrated to primary standards, another disadvantage is the relatively large size of the probe and therefore its limited spatial resolution compared with other methods. While the standard deviation of image analysis and Feritscope is a matter of the different ferrite contents within a single bead, the standard deviation of the Magne-Gage measurements is due to its poor reproducibility. Here, the absence of an experienced operator probably played a significant role. Although there are plenty of results showing that a well-calibrated Magne-Gage, used by an experienced operator does not give a large standard deviation, the instrument is not the quickest and easiest method to use.

The best agreement in the results was observed for the image analysis and the Feritscope for the samples with one layer/one bead and two layers/three beads. Still, the Feritscope values are systematically lower than the results of image analysis. The Feritscope analyzes approximately a volume of $10 \mathrm{~mm}^{3}$. Therefore, a minimum dimension of the sample and a certain distance from the probe to the edge of the sample is necessary. If this requirement is not given, a drop in the measured FN values will occur. This is known as the edge effect [25]. Manufacturers of duplex filler metals prefer to be
Fig. 13 Comparison of ferrite content between image analysis $($ magnification $\times 500$ ) and Feritscope

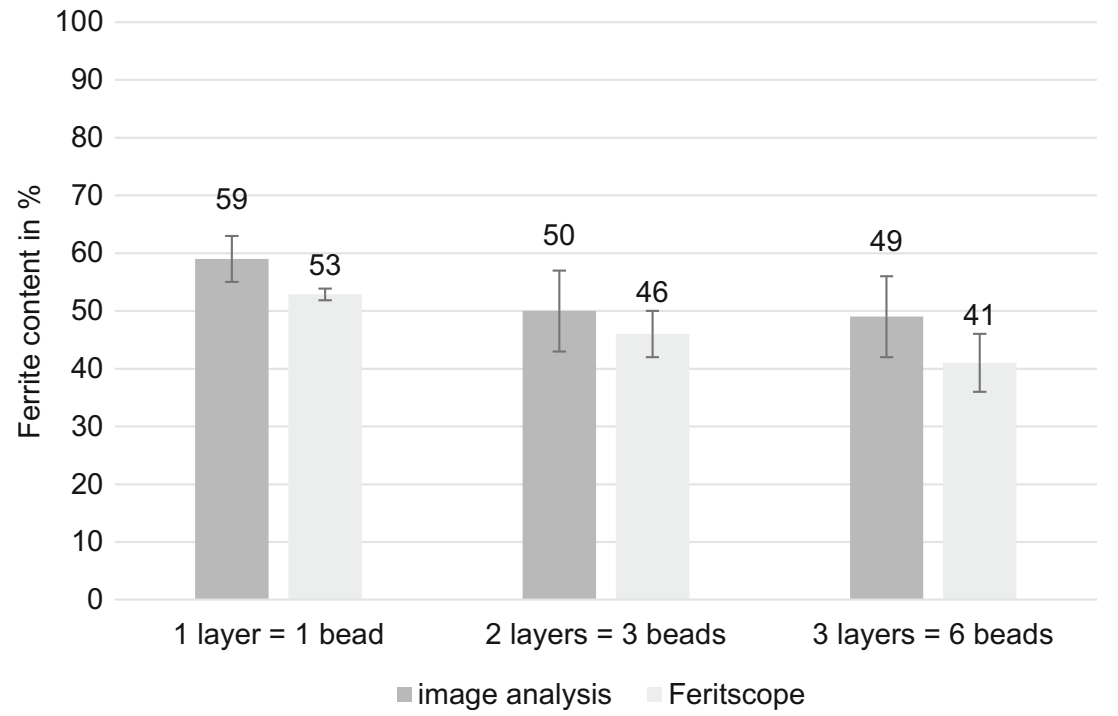


Fig. 14 Internal conversion of FN to $\%$ ferrite given for the Feritscope [23]

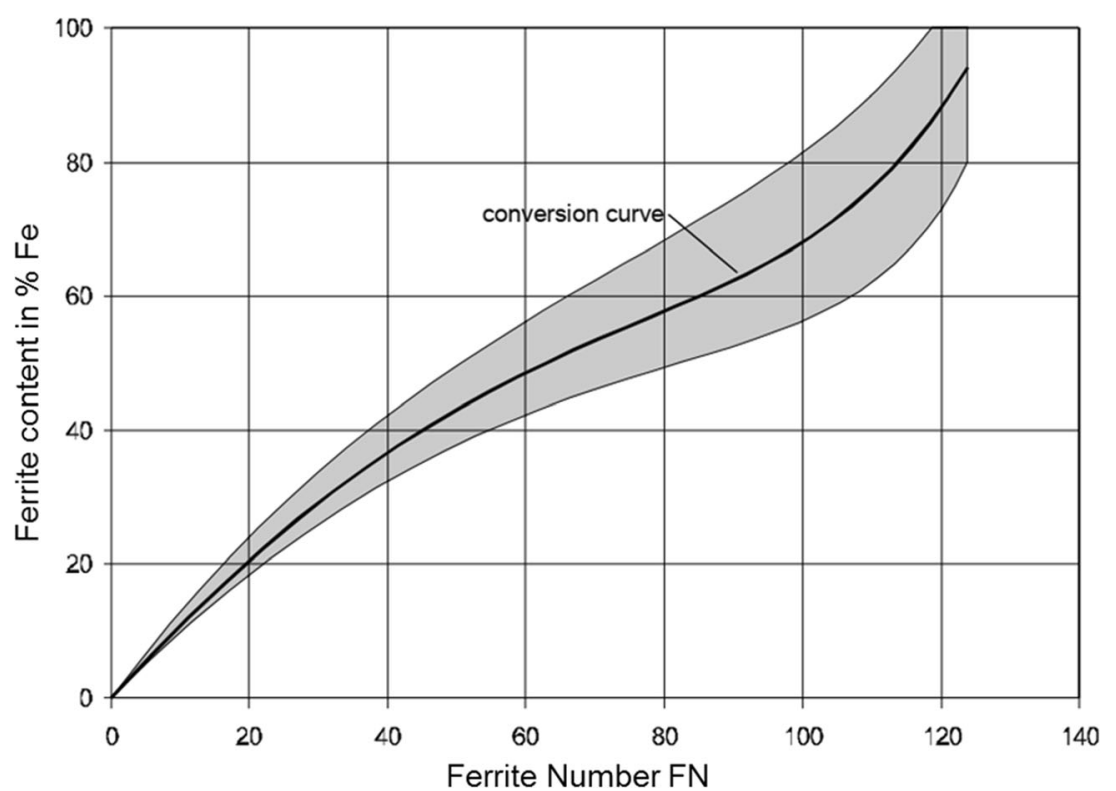

on the lower side of the ferrite content by adding nickel for an improved impact toughness. If not taking the conversion factor of 1.1 times the value measured with the Feritscope into consideration, it is possible that welds may not pass the requirements.

The XRD measurements proved to be unsuitable for determining the ferrite content, and this is believed to be caused by the grain morphology. A reliable XRD measurement requires that there are several small grains with random orientation in the XRD beam [26]. The weld consists of fairly large ferrite grains while the austenite grains are smaller. Also, the ferrite grain growth during solidification will take place in $<100\rangle$ crystallographic direction [27]. Therefore, the experimental setup for $\mathrm{XRD}$ analysis in this work was not a well-suited technique for ferrite quantification in duplex stainless steel welds.
Regardless of the measuring method, the ferrite content decreased as the number of weld layers increased. There are two main explanations: the formation of secondary austenite on reheating and the addition of nickel through the filler metal. The first pass melts more base material and will be somewhat more diluted in nickel than the following layers. The root pass thus showed a fairly high ferrite content, but the austenite fraction increased somewhat on reheating by subsequent weld passes. The austenite formation was more pronounced in the following pass/layer, and this is suggested to be a result of nickel additions from the filler wire and less dilution from the parent material. The final weld bead again showed a higher ferrite content as it is not reheated by any further welds and somewhat more diluted from the vertical base material. This complex change of the ferrite content can
Fig. 15 Comparison of ferrite number between Feritscope and Magne-Gage
140

120

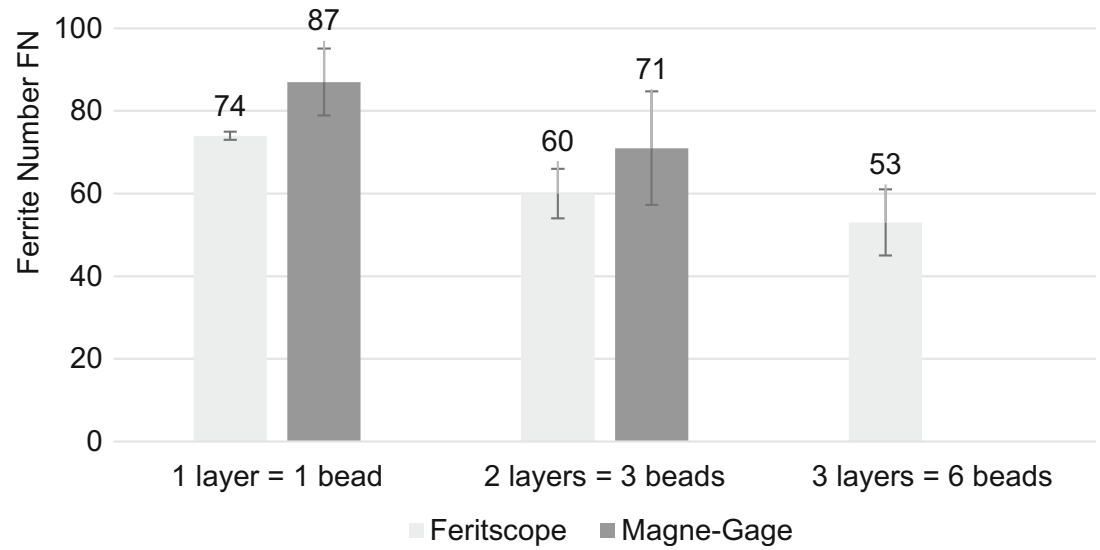


be observed in Fig. 5. The variation of ferrite content within each bead can be significant.

It is known that the use of pure $\mathrm{CO}_{2}$ as shielding gas may lead to somewhat higher weld metal austenite content [28]. Worst case, this can lead to a phase balance outside the specification and affects the mechanical properties. For the particular flux-cored wire in the examined multipass welds, the average ferrite content was $54 \pm 5 \%$ according to image analysis. This is within the stricter 35-65\% limit set for the phase analysis in NORSOK M-601 [9] and thus fulfills most industry specifications.

\section{Conclusions}

The effect of multipass welding on the ferrite content was investigated for a $22 \mathrm{Cr}$ duplex stainless steel welded with a matching flux-cored arc wire over-alloyed in nickel. Four different methods were used to determine the phase balance: image analysis, Feritscope, Magne-Gage, and XRD. The following conclusions could be drawn:

- Among the typically recommended etchants, modified Beraha II proved most suitable for this material combination for image analysis.

- In addition to the advantage of having an actual image for reporting and for comparison, image analysis is considered to be the most accurate method for measuring the weld metal ferrite content.

- The highest surface quality with most uniform etching was obtained when covering all surfaces that were not examined with an adhesive tape.

- It was possible to optimize the time for determining the ferrite content by reducing the number of measurements from five images to one per area of interest and still having a comparable mean value and standard deviation.

- The Feritscope is designed to measure ferrite numbers, and a conversion curve is used to change the values into percent ferrite. Compared with image analysis, the percent ferrite will be approximately $10 \%$ lower compared with image analysis and a correction factor of 1.1 is suggested.

- Although the XRD technique is a well-known method for measurement of different fractions in structures, the acclaimed method was not suitable for measuring the ferrite content of these DSS welds.

- In this study, the Magne-Gage instrument showed higher ferrite numbers and a larger standard deviation than the Feritscope and a correction factor of 1.18 is suggested.

- The limitations of the individual methods should be considered carefully if the measured ferrite content is close to the limit of the specification and especially when multipass welding.
Acknowledgments Open access funding provided by Graz University of Technology. The authors would like to thank Ing. Andrea Maderthoner (voestalpine Böhler Welding Austria $\mathrm{GmbH}$ ) for her provided knowledge about welding of DSS and the chemical analysis, Prof. Leif Karlsson (University West) and Martin Jernberg (ESAB AB) for providing the Magne-Gage device, and Dr. Sten Wessman and Dr. Fredrik Lindberg (Swerim AB) for performing the XRD measurements.

Funding information Recommended for publication by Commission IX - Behaviour of Metals Subjected to Welding.

Open Access This article is distributed under the terms of the Creative Commons Attribution 4.0 International License (http:// creativecommons.org/licenses/by/4.0/), which permits unrestricted use, distribution, and reproduction in any medium, provided you give appropriate credit to the original author(s) and the source, provide a link to the Creative Commons license, and indicate if changes were made.

\section{References}

1. Gunn RN (1997) Duplex stainless steels: microstructure, properties and applications. Woodhead Publishing Ltd., Cambridge, England. $216 \mathrm{pp}$

2. Knyazeva M, Pohl M (2013) Duplex steels: part I: genesis, formation, structure. Metallography, Microstrucutre and Analysis 2:113 121. https://doi.org/10.1007/s13632-013-0066-8

3. Karlsson L (2000) Welding of stainless steels. Duplex and superduplex steels. Weld Int 14:5-11. https://doi.org/10.1080/ 09507110009549131

4. Holmberg (1997) How to perform welding in duplex stainless steels to obtain optimum weld metal properties. Stainless Steel World 9:2: 28-33 / ACOM 13:3:1-7

5. Valiente Bermejo MA, Eyzop D, Karlsson L, Svensson L-E, Hurtig $\mathrm{K}$ (2017) Influence of multi-pass welding on the microstructure and properties of superduplex stainless steels. IIW Doc IX-2607-17 / IX-H-844-17. 43pp

6. Tamaki K, Yasuda K, Kimura M (1989) Corrosion performance of girth weld joints of duplex stainless steels. Corrosion 45:764-770

7. Verma J, Taiwade RV, Sonkusare R (2017) Effects of austenitic and duplex electrodes on microstructure, mechanical properties, pitting, and galvanic corrosion resistance of ferritic and dual-phase stainless steel dissimilar joints. J Mater Res 32:3066-3077. https://doi.org/ 10.1557/jmr.2017.269

8. Varol I, Baeslack WA, Lippold JC (1989) Characterization of weld solidification cracking in a duplex stainless steel. Metallography 23: 1-19. https://doi.org/10.1016/0026-0800(89)90037-2

9. Standards Norway (2008) Norsok standard M-601 welding and inspection of piping. Lysaker, Norway. 24pp

10. Schaeffler A (1949) Constitution diagram for stainless steel weld metal. Metal Progress 56:680

11. Delong WT (1974) Ferrite in austenitic stainless steel weld metal. Weld J 53(7):273s-286s

12. Kotecki DJ, Siewert TA (1992) WRC-1992 constitution diagram for stainless steel weld metals: a modification of the WRC-1988 diagram. Welding Research Supplement:171-178. https://doi.org/ 10.1007/978-1-61779-582-4

13. Kotecki D, Siewert TA (1993) A new constitution diagram for predicting ferrite content of stainless steel weld metals. Mater Des 14:345-348. https://doi.org/10.1016/0261-3069(93)90110-H

14. Vander Voort G.F. (1999) Metallography: principles and practice. ASM International, Materials Park, United States of America. $425 \mathrm{pp}$ 
15. Forgas Júnior A, Otubo J, Magnabosco R (2016) Ferrite quantification methodologies for duplex stainless steel. J Aerosp Technol Manag 8:357-362. https://doi.org/10.5028/jatm.v8i3.653

16. Niagaj J, Mazur $€$ (2014) Review of methods for measurement of ferrite content in high alloyed steels and their welded joints. Weld Int 28:345-353. https://doi.org/10.1080/09507116.2012.708490

17. Behal VG, Melilli AS (1982) Stainless steel castings. American Society for Testing and Materials. American Society for Testing and Materials. Committee A-1 on Steel, Stainless Steel 11pp

18. Leng Y (2008) Materials characterization: introduction to microscopic and spectroscopic methods. John Wiley \& Sons Ltd., Singapore. 384pp

19. Petzow G (2015) Metallographisches, Keramographisches, Plastographisches Ätzen. Borntraeger Gebrueder. 298pp

20. ASTM E562-11 (2002) Standard test method for determining volume fraction by systematic manual point count. ASTM B Stand 17. https://doi.org/10.1520/E0562-11.2

21. Westin EM, Herzman S (2014) Element distribution in lean duplex stainless steel welds. Welding in the World 58:143-160

22. Hosseini VA, Hurtig K, Eyzop D, Östberg A, Janiak P, Karlsson L (2018) Ferrite content measurement in super duplex stainless steel welds In press: Weld World 13pp. DOI: https://doi.org/10.1007/ s40194-018-00681-1

23. Operating Manual (2001) Feritscope $®$ MP30. 30:1-212

24. ANSI / AWS A4.2M / A4.2 (1997) Standard procedures for calibrating magnetic instruments to measure the delta ferrite content of austenitic and duplex ferritic-austenitic stainless steel weld metal, $31 \mathrm{pp}$

25. Valiente Bermejo MA (2012) Predictive and measurement methods for delta ferrite determination. Weld J 91:113-121

26. ASTM E975-13 (2009) Standard practice for X-ray determination of retained austenite in steel with near random crystallographic orientation. ASTM 03:1-7. https://doi.org/10.1520/E0975-13

27. Stefanescu D, Ruxanda R (2004) Fundamentals of solidification. In: ASM handbook - metallography and microstuctures, George van. ASM International, pp 71-92

28. Kah P, Martikainen J (2013) Influence of shielding gases in the welding of metals. Int J Adv Manuf Technol 64:1411-1421. https://doi.org/10.1007/s00170-012-4111-6

Publisher's note Springer Nature remains neutral with regard to jurisdictional claims in published maps and institutional affiliations. 